\section{Tachypnoea in a well baby: what to do next?}

\author{
Ian M Balfour-Lynn, ${ }^{1}$ Michael L Rigby ${ }^{2}$
}

It is not uncommon to see babies in clinic who have been referred because they are persistently tachypnoeic. Sometimes this has been noticed by the parents, but more often, especially if it is the parents' first baby, they do not realise anything is amiss, and it is the midwife, health visitor or general practitioner who brings it to their attention. Occasionally it has been noted as early as the postnatal ward. This article outlines a management approach to a term baby with tachypnoea in an outpatient setting, and is not focusing on acutely unwell infants (figure 1). It is taken from the perspective of a referral to a general paediatric clinic, although these babies are also often referred straight to a respiratory clinic.

\section{WHAT IS TACHYPNOEA?}

Aside from the huge physiological changes that occur at birth, in the postnatal period there are substantial changes in the resting breathing pattern of babies, notably a slowing of the rate and a lengthening of inspiration. Paradoxical chest wall movements and short apnoeic pauses (>2 s) during sleep decrease over several months. Infants may also exhibit periodic breathing, which is a pattern of short respiratory pauses $(<6 s)$ that occur in groups of three or more, with less than $20 \mathrm{~s}$ of respiration between pauses; the pause is usually followed by a series of rapid shallow breaths. In full term babies periodic breathing is more common during sleep, and is usually seen from 1 week to 2 months of age; it tends to disappear by 6 months and is of no consequence. ${ }^{1}$ The normal respiratory rate gradually decreases over the 1 st year (figure 2). There is no gender difference and the rate is higher in awake babies. ${ }^{2}$

\section{IS THE BABY TACHYPNOEIC?}

Measuring the respiratory rate is not always easy, especially if the baby is moving or crying; both these increase the rate, and the state of the baby (especially

\footnotetext{
${ }^{1}$ Departments of Paediatric Respiratory Medicine, Royal Brompton Hospital, London, UK; ${ }^{2}$ Paediatric Cardiology, Royal Brompton Hospital, London, UK

Correspondence to Dr lan M Balfour-Lynn, Royal Brompton Hospital, Sydney Street, London SW3 6NP, UK; i.balfourlynn@ic.ac.uk
}

awake vs asleep) should be recorded alongside the rate. Many babies do not breathe in a regular manner, but often have brief pauses or runs of panting. It is easier to use a stethoscope to listen for breaths rather than simply watching the baby's chest. Auscultation usually gives a higher rate, presumably due to missed breaths from observation alone. ${ }^{2}$ The rate needs to be measured over a full minute (or the sum of two sets of $30 \mathrm{~s}$ ), and will need to be repeated a few times if it is variable. $^{3}$ Counting for $30 \mathrm{~s}$ and doubling the figure results in a higher mean count by two to four per minute, and quadrupling a $15 \mathrm{~s}$ count may further increase the difference. ${ }^{4}$ Respiratory monitors are not usually required but can be helpful, for example a Graseby MR10 Neonatal Respiration Monitor (Sims Graseby, Watford, UK) which can be used on babies less than 18 months of age. The advantage is that once the foam pad is attached to the abdomen, the baby can be wrapped up and allowed to settle without being disturbed by a cold stethoscope on its skin. They function better when the baby is asleep as, if awake, there may be too much motion artefact to interpret the respiratory signal. ${ }^{5}$ Using the prototype of this monitor in the late $1970 \mathrm{~s}$, it was found that only $1 \%$ of 2789 newborn infants had a respiratory rate $>60 / \mathrm{min}^{6}$

\section{IS THE BABY UNWELL?}

Given the baby has been referred to an outpatient clinic, it is likely the child is not acutely unwell. Nevertheless it is important to be certain, and if it is an issue, the child may need to be admitted to hospital. Clearly an acute lower respiratory tract infection (including bronchiolitis) must be excluded. The WHO threshold for tachypnoea, as an aid to diagnosing acute respiratory infections and the need for antibiotics, is set at 60 breaths/ $\mathrm{min}$ for infants $<2$ months, and 50 breaths/min for those aged 2-12 months. ${ }^{4} 5$ However the rate alone is not necessarily diagnostic of infection or associated with the severity of the respiratory illness, as the normal range is so wide in healthy babies. ${ }^{5}$ Fever is associated with tachypnoea, and every $1^{\circ} \mathrm{C}$ above $37^{\circ} \mathrm{C}$ raises the rate by approximately 5-7 bpm. ${ }^{1}$ Certain symptoms elicited from the history at this stage are red flags for concern of a significant underlying condition (box 1). Consider also the possibility of a foreign body when an older sibling may have put something in the baby's mouth.

\section{IS THE EXAMINATION NORMAL?}

Clinical examination is important, with some red flag warning signs (box 2). The child's colour is important (cyanosis, paleness). In addition to the respiratory rate, other signs of respiratory distress must be looked for, including intercostal and subcostal recession, and tracheal tug, use of accessory muscles, grunting, and nasal flaring. Some well babies with tachypnoea have a degree of recession as the only other clinical sign. Obviously the presence of crackles, wheeze and stridor is important for the diagnosis. Paradoxical breathing, an inward movement of the chest wall during inspiration, often with a seesaw thoracoabdominal motion, must be looked for (neuromuscular disease, diaphragmatic abnormality, upper airway obstruction). The shape of the thorax is checked to ensure normal dimensions (eg, very small in asphyxiating thoracic dystrophy, bellshaped in pulmonary hypoplasia). The presence of persistent rhinitis should make one consider primary ciliary dyskinesia.

Examination focused specifically on the cardiovascular system is also important and often neglected. Central cyanosis is most evident in the mouth, and the cardiac apex may be visibly displaced if there is cardiomegaly. Precordial palpation may reveal a right-sided impulse in Scimitar syndrome, or complex forms of congenital heart disease associated with atrial isomerism (visceral heterotaxy or a mirror image arrangement in primary ciliary dyskinesia). A prominent precordial impulse is an important sign of cardiovascular disease with pressure or volume overload of the heart. Femoral pulses which are weak or difficult to feel (coarctation of the aorta), or generally weak pulses (myocarditis, dilated cardiomyopathy, severe aortic stenosis or other forms of left heart obstruction) can be important signs. Liver enlargement is usually a manifestation of heart failure, but can be palpable if it is displaced by overinflated lungs. Unusually soft or loud heart sounds, ejection clicks, wide splitting of the second heart sound, a loud P2 or a heart murmur may indicate a cardiovascular cause. However, particularly in the newborn, heart murmurs are very common, while significant congenital heart disease during infancy is often not accompanied by a heart murmur. Always listen over the skull and particularly the occiput for the murmur of a cerebral arteriovenous 
Figure 1 Algorithm for management of a baby with tachypnoea. CXR, chest radiograph; $\mathrm{SpO}_{2}$, oxygen saturation.

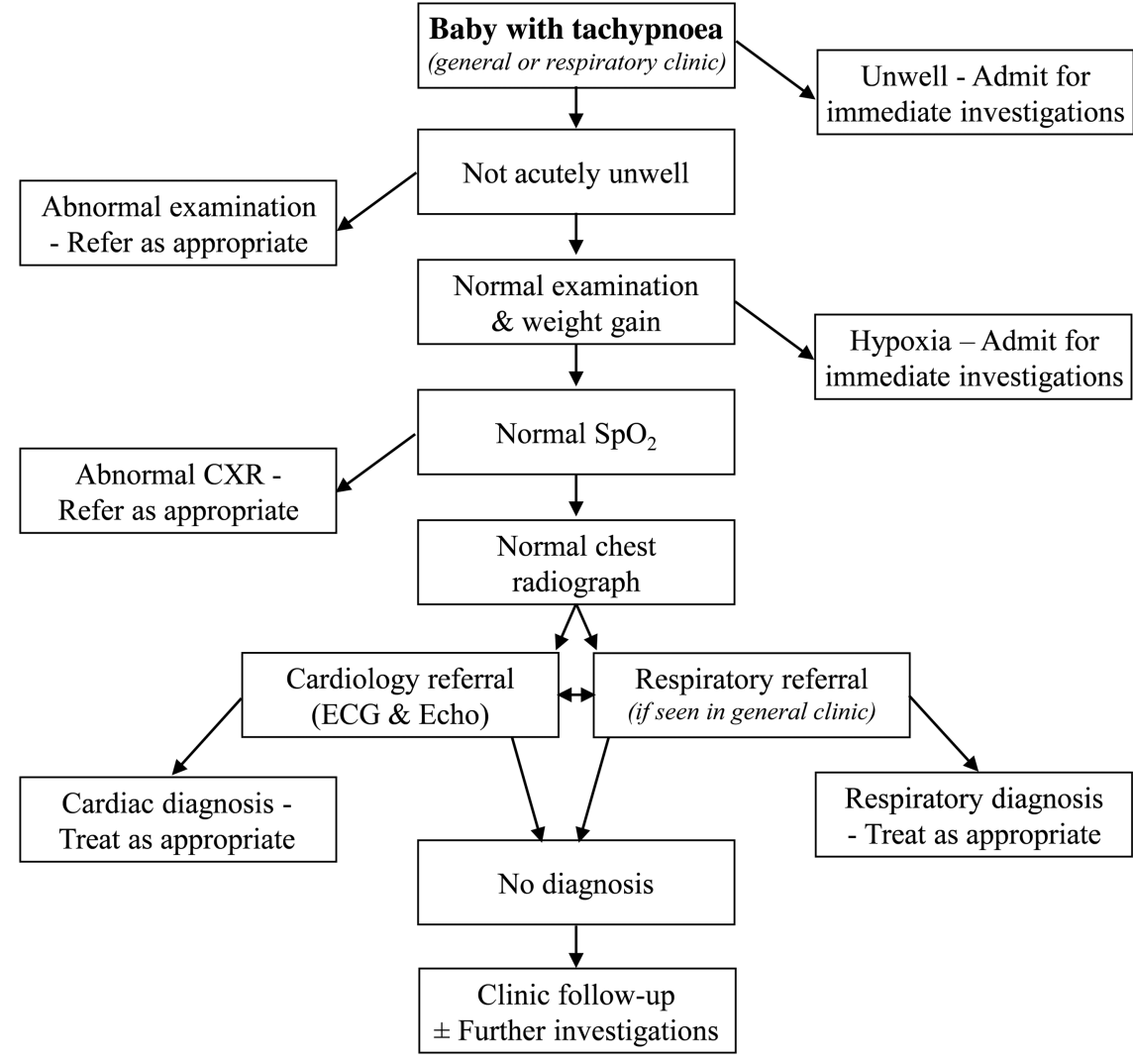

fistula, whose only clinical manifestation might be tachypnoea. Thus whenever tachypnoea has a cardiovascular cause, even without a heart murmur there is usually a clinical pointer to a cardiac anomaly.

The child's weight, height and head circumference will give an indication of faltering growth which may be secondary to tachypnoea or an underlying condition. Abdominal examination is done to exclude an enlarged liver or spleen, or an abdominal mass. A basic neurological examination is done, particularly for hypotonia which may indicate a neuromuscular disorder. The patency of the

nose must be examined to exclude choanal stenosis or unilateral atresia (it may be necessary to pass a nasogastric tube down both sides).

\section{IMMEDIATE CLINIC INVESTIGATIONS}

Oxygen saturation $\left(\mathrm{SpO}_{2}\right)$ is the most important initial investigation. This is measured by pulse oximetry and an appropriately sized finger/toe probe must be used, preferably with the baby not crying. The median baseline $\mathrm{SpO}_{2}$ in healthy term infants during the 1 st year of life is $97-98 \%$. $^{7}$ There have been two longitudinal studies of $\mathrm{SpO}_{2}$ in infants over

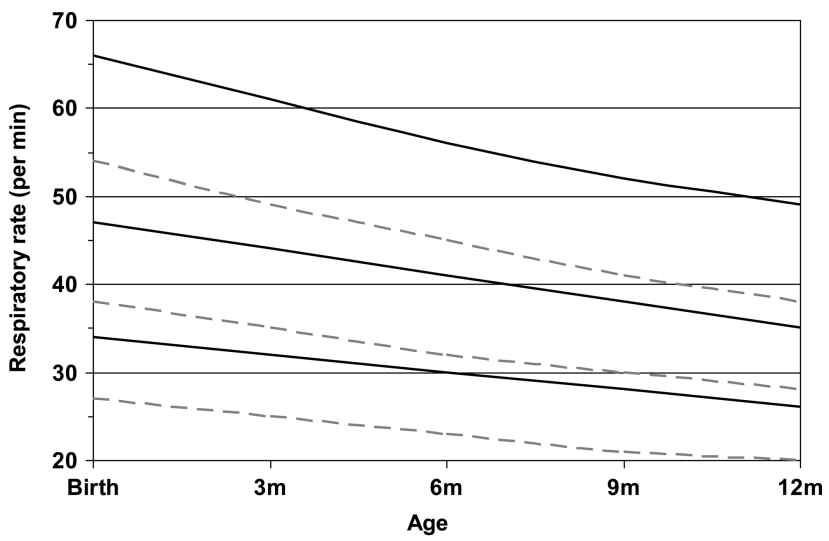

Figure 2 Respiratory rate in 1st year of life, awake (solid line) and asleep (dashed line), showing 5th, 50th and 95th centiles. Adapted from Rusconi et al. ${ }^{2}$

their first 6-12 months, one showed a slight increase with age, ${ }^{8}$ the other found no increase in baseline but did see a reduction in variability. ${ }^{9}$ Certainly if the baby has a low $\mathrm{SpO}_{2}$, the urgency of the situation and need for further investigations are heightened; our cut-off for immediate action is $94 \%$ or below. It may be necessary to measure preductal and postductal saturations, with a probe on the right hand and either foot. Pulse oximetry is a useful screening tool for detection of certain types of congenital heart diseases (eg, total anomalous pulmonary venous drainage, truncus) in the postnatal period. ${ }^{10}$

If the $\mathrm{SpO}_{2}$ is significantly low $(<85 \%)$, one should consider a hyperoxia test. ${ }^{11}$ If the pulse oximetry $\mathrm{SpO}_{2}$ remains $<85 \%$ in $100 \%$ oxygen, a formal test is carried out with arterial blood gases or transcutaneous oxygen monitoring from the right

\section{Box 1 Red flag symptoms}

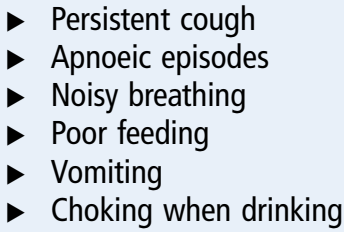




\section{Box 2 Red flag signs}

- Respiratory distress

- Cyanosis

- Cardiac murmur

- Abnormal femoral pulses

- Hepatomegaly

- Hypotonia

arm after administration of $100 \%$ oxygen for 5-10 min. If supplemental oxygen does not improve the partial pressure of oxygen in arterial blood $\left(\mathrm{PaO}_{2}\right)$, cyanotic congenital heart disease or some form of right to left shunting must be considered with an immediate cardiology assessment. If there is a rise in $\mathrm{PaO}_{2}$, this points more towards a respiratory cause.

The following is a useful guide: ${ }^{12}$

- $\mathrm{PaO}_{2}>33 \mathrm{kPa}$-excludes cyanotic heart disease

- $\mathrm{PaO}_{2}>26 \mathrm{kPa}$ - cyanotic heart disease very unlikely

- $\mathrm{PaO}_{2}<13 \mathrm{kPa}$-cyanotic heart disease extremely likely

Chest radiography is the other initial investigation. Clarity of the lung fields is important. If abnormal, the radiograph may indicate a number of potential diagnoses that would require further investigation and treatment. Some of the conditions that the radiograph may point to are infection (including congenital tuberculosis); air leaks such as pneumothorax or pneumomediastinum; pleural effusion including chylothorax; aspiration from gastro-oesophageal reflux, a swallowing abnormality or H-type tracheo-oesophageal fistula; interstitial lung disease; congenital thoracic malformation; Scimitar syndrome; congenital diaphragmatic hernia (CDH). Heart size, shape and position may indicate cardiac disease. The integrity of the diaphragm is checked (eventration, hernia, paralysis). Chest shape and size are assessed (eg, bell-shaped in pulmonary hypoplasia), as well as the ribs themselves, which may have the classic abnormalities of severe neonatal rickets, or be very thin (gracile) in neuromuscular disease. Additionally, as with any unexplained symptom in children, non-accidental

\section{Box 3 Red flag initial investigations}

- Hypoxia (oxygen saturation $\left(\mathrm{SpO}_{2}\right)$ $\leq 94 \%)$

- Abnormal chest radiograph injury must be considered and the ribs checked for fractures.

\section{CARDIOLOGY AND RESPIRATORY REFERRAL}

At this stage, a well baby with tachypnoea (with or without some recession), who has a normal $\mathrm{SpO}_{2}$ and chest radiograph, can leave clinic and go home with follow-up in 4 weeks, or sooner if the clinical picture changes. However the child should always be referred immediately to a paediatric cardiologist, as well as a paediatric respiratory specialist (unless the initial referral was to a tertiary respiratory clinic).

\section{FURTHER INVESTIGATIONS}

Generally the babies remain well and gradually the degree of tachypnoea reduces with time. However if there is no improvement, and especially if the degree of respiratory distress increases, further investigations become necessary. In order to identify the major causes outlined below, the second wave of investigations may well include the following:

- CT chest scan-this can be done without the need for sedation in most infants, using the 'feed and wrap' technique. ${ }^{13}$ There is no need for a contrast-enhanced scan at this stage.

- Dual probe 24-h pH study.

- Swallowing assessment-clinical evaluation and videofluoroscopic swallowing study.

- Ultrasound or fluoroscopic screening of the diaphragms.

\section{POTENTIAL CAUSES OF TACHYPNOEA -WHEN THE DIAGNOSIS IS NOT IMMEDIATELY OBVIOUS}

There are numerous causes of tachypnoea in term infants (reviewed by Sasidharan ${ }^{11}$ ). Often the tachypnoea is just one of several signs in a clearly unwell child, examples include, a baby with a metabolic acidosis for example from numerous rare metabolic disorders; bacterial sepsis; or significant pain, for example, from a volvulus. In some children, the cause is obvious on initial assessment, from the history, for example, narcotic withdrawal and postbirth asphyxia. In some, it may be determined on first examination, for example, the small thorax of Jeune asphyxiating thoracic dystrophy, bell-shaped chest from pulmonary hypoplasia, hypotonia associated with neurological or neuromuscular disease, stridor due to upper airway obstruction or even severe neonatal rickets.

Below are some causes to consider in a child who seems well, has a normal clinical examination, but is without an immediately obvious diagnosis, with the relevant investigations that may provide the answer.

\section{Respiratory and upper airway}

Infection. It is likely the child would have other symptoms and signs, particularly fever and cough, nevertheless, low grade or chronic infection must be considered. A nasopharyngeal aspirate for respiratory viruses and a cough swab for bacterial culture, and possibly a white cell count and $\mathrm{C}$ reactive protein may be helpful. Pulmonary tuberculosis has been described in children under 1 year, with tachypnoea the predominant sign, and not all patients had a contact history, cough or abnormal radiograph, although most did. ${ }^{14}$

Cystic fibrosis. In the UK and many other countries, newborn screening means babies are diagnosed with cystic fibrosis (CF) at around 3-4 weeks of age; however screening is not infallible. While most babies are symptom-free from the respiratory perspective, the majority have suboptimal weight gain, often with abnormal stools. Infants can present with tachypnoea, recurrent cough and sometimes wheeze, ${ }^{15}$ but our experience is that it is most unusual for tachypnoea to be the sole symptom in a baby with CF. Nevertheless it must be considered and a sweat test performed if appropriate.

Interstitial lung disease. This is a heterogeneous group of rare diseases, most often accompanied by crackles, recession, hypoxaemia and eventually failure to thrive. ${ }^{16}$ However in some, tachypnoea is the only obvious symptom, and the severity of symptoms and signs varies. Consideration should be given to neuroendocrine cell hyperplasia, previously known as persistent tachypnoea of infancy; it is often associated with recession, crackles in the chest and sometime hypoxia. ${ }^{17}$ There is an airway obstruction element to the condition, but the prognosis is generally good, with symptoms resolving at a median of 18 months (range 6-60 months), although in practice it may be even longer. ${ }^{18}$ Inherited surfactant protein $\mathrm{C}$ deficiency, ATP-binding cassette transporter $\mathrm{A} 3$ and thyroid transcription factor-1 are important, although again other signs of respiratory distress are likely to be present. ${ }^{19}$ Surfactant protein B deficiency is lethal in neonates so is unlikely to present with just tachypnoea. ${ }^{16}$ A chest CT scan can be highly suggestive, although diagnostic certainty may require a lung biopsy. In cases of neuroendocrine cell hyperplasia, the appearance is quite 
characteristic with ground glass opacification, particularly in the right middle lobe and lingula, accompanied by air trapping and mosaicism. ${ }^{20}$ Blood for surfactant protein gene mutations can diagnose surfactant protein B and C deficiency, ATP-binding cassette transporter A3 and thyroid transcription factor-1 (NKX2.1) gene abnormalities.

Congenital thoracic malformations, particularly cystic ones, are usually asymptomatic and diagnosed antenatally during fetal abnormality ultrasound scanning. However congenital lobar emphysema may cause neonatal respiratory distress, and while symptoms may be present at birth or appear within the first $48 \mathrm{~h}$, in some cases tachypnoea does not develop for 1-4 months. ${ }^{21}$ Furthermore, although usually obvious on a plain chest radiograph, a case has been reported in which the lesion was only apparent on a CT scan. ${ }^{21}$ Rarely, forms of spontaneous pulmonary interstitial emphysema have been seen with minimal respiratory symptoms, including tachypnoea, in a full term nonventilated baby; a chest radiograph and CT scan indicate the diagnosis. ${ }^{22}$

Pulmonary hypoplasia. This is rarely an isolated phenomenon (primary) ${ }^{23}$ and more commonly is secondary and associated with disorders of lung growth (eg, severe oligohydramnios, CDH, Ebstein's malformation of the tricuspid valve). ${ }^{24}$ Patients may present in early infancy, and the severity depends on the degree of hypoplasia; persistent tachypnoea and breathlessness with activity/exercise are the principle symptoms when the hypoplasia is not too severe. When unilateral, the thorax is asymmetrical, with reduced air entry and underexpansion on that side. Confirmation can usually be made with a chest radiograph or a chest CT scan. With normal radiology, infant lung function testing may be necessary which would indicate reduced lung volumes and reduced functional residual capacity. ${ }^{23}$ If right sided, the pulmonary vasculature must be visualised because of the association with Scimitar syndrome (partial or complete anomalous pulmonary venous drainage into the inferior vena cava, commonly associated with persistent left superior vena cava, dextrocardia, pulmonary sequestration and right pulmonary hypoplasia). ${ }^{25}$ The infantile form of Scimitar tends to present in the first 2 months with tachypnoea, as well as recurrent pneumonia, failure to thrive and heart failure. $^{25}$

Congenital diaphragmatic hernia. This lesion is often diagnosed antenatally or within hours or days of birth. However late-presenting ( $>1$ month) $\mathrm{CDH}$ is well recognised, and a review of these late diagnoses found $65 \%$ of right sided and $42 \%$ left sided $\mathrm{CDH}$ presented within the 1 st year of life. ${ }^{26}$ Tachypnoea was the most common symptom, followed by vomiting. Diagnosis may be made on a chest radiograph but is not always obvious; chest CT or a contrast gastrointestinal study may be necessary.

Diaphragmatic weakness. Compared with adults, the diaphragm is critical to respiration in infancy due to the fact the chest wall is so compliant, the mediastinum is more mobile and the intercostal muscles are weaker. ${ }^{27}$ Even unilateral diaphragmatic weakness can cause a degree of respiratory distress. At this age, phrenic nerve injury is the most common cause. When due to a difficult delivery, for example, following shoulder dystocia, the majority of infants with phrenic nerve palsy also have a brachial plexus injury (Erb's palsy). ${ }^{27} \mathrm{~A}$ number of congenital neuromuscular disorders can cause severe diaphragmatic weakness. One of them, spinal muscular atrophy with respiratory distress (SMARD1) is very rare and unlike more typical spinal muscular atrophies, presents with respiratory distress before distal muscular weakness is obvious. The respiratory difficulty is due to diaphragmatic weakness followed by paralysis (more usually on the right side initially), but it is usually accompanied by a weak cry and stridor. ${ }^{28} \mathrm{~A}$ chest radiograph may indicate an abnormal position of a hemidiaphragm. An ultrasound or fluoroscopic examination of the diaphragms can demonstrate abnormal movements, especially if paradoxical or weak/paralysed.

H-type tracheo-oesophageal fistula. It is likely that as well as tachypnoea, the child would have marked symptoms on feeding, usually coughing, choking, turning blue and potentially recurrent lung infections. A tube oesophagram (video oesophagography) and/or bronchoscopy may be necessary to make the diagnosis, however.

Upper airway narrowing may be obvious due to the presence of significant or persisting stridor, especially if the narrowing is more than mild. Possible causes include laryngotracheomalacia, bronchomalacia, laryngeal or tracheal web, subglottic stenosis. Tachypnoea accompanied by noisy breathing is an indication for a bronchoscopy (flexible or rigid).

Nasal obstruction. Infants are obligate nose breathers for several months. Nasal obstruction, when bilateral, can cause significant respiratory distress in the neonatal period, and intubation may be required, for example, bilateral choanal atresia. ${ }^{29}$
However unilateral obstruction may present later (typically at 5-24 months), and with milder symptoms ${ }^{30}$; unilateral atresia is more common than bilateral and accounts for up to $75 \%$ cases of atresia. Additionally symptoms will be milder if it is a stenosis rather than complete atresia. Techniques for diagnosis include placing a cold mirror/metal spoon under the nostril to look for condensation, passing a small nasogastric tube, or putting a few drops of saline in the nostril and looking for bubbles. $^{29}$

\section{Cardiac}

After careful examination by the cardiologist, inevitably children will have an ECG and echocardiogram performed to exclude a number of potential cardiac diagnoses. It is important to be aware that major cardiovascular disease may present initially during infancy with just mild tachypnoea. With increasing symptoms of tachypnoea and recurrent chest infections, cardiac disorders may masquerade as respiratory disease. ${ }^{30-32}$ Many causes are 'silent' meaning there is no murmur, so the diagnosis is not always obvious without assessment by a cardiologist (box 4).

Tachypnoea during infancy without a heart murmur can occasionally be caused by a large atrial septal defect, pulmonary vein stenosis, cor triatriatum, mitral stenosis, hypertrophic cardiomyopathy and coarctation of the aorta. Transient neonatal myocardial ischaemia complicating birth asphyxia, ${ }^{33}$ anomalous origin of a coronary artery from the pulmonary trunk, dilated cardiomyopathy and myocarditis ${ }^{34}$ will manifest ' $\mathrm{T}$ ' wave abnormalities and ischaemia or infarction on an ECG.

'Silent' heart disease in infants with pulmonary hypertension and a persistent elevation of pulmonary vascular resistance for several weeks ${ }^{35} 36$ may sometimes be associated with a large ventricular septal defect, complete atrioventricular septal defect (especially in babies with Down's Syndrome), large patent ductus arteriosus and common mixing situations in which mild arterial oxygen desaturation is not clinically obvious. ${ }^{37-39}$ Infants without heart disease may manifest a failure of a fall in pulmonary vascular resistance after birth, leading to mild tachypnoea, which can be a mild form of persistent pulmonary hypertension of the newborn. ${ }^{36}$ Almost all of these infants with pulmonary hypertension will have a prominent precordial impulse, loud pulmonary component of the second heart sound, right ventricular hypertrophy on an ECG, and cardiomegaly with or without pulmonary venous congestion on a chest radiograph. 
Box 4 Potential cardiovascular

causes of 'silent' tachypnoea

Left to right shunts

- Large atrial septal defect

- Large ventricular septal defect

- Complete atrioventricular septal defect

- Large patent ductus arteriosus

Common mixing situations

- Total anomalous pulmonary venous drainage

- Scimitar syndrome

- Functionally single ventricle without pulmonary stenosis

- Tricuspid atresia

- Double inlet ventricle

- Common arterial trunk

- Aortopulmonary window

- Cerebral arteriovenous fistula

Left heart obstruction

- Cor triatriatum

- Mitral stenosis

- Severe aortic stenosis

- Coarctation of aorta

Heart muscle disease

- Transient myocardial ischaemia

- Myocarditis

- Dilated cardiomyopathy

- Hypertrophic cardiomyopathy

- Anomalous origin of coronary artery

Pericardial effusion

Pneumopericardium

Vascular airway compression:

- Vascular ring

- Pulmonary artery sling

Primary pulmonary hypertension

Whatever the cardiac anomaly, a good quality echocardiogram will usually provide a complete diagnosis. When tachypnoea without obvious stridor results from a vascular ring or pulmonary artery sling, ${ }^{40}$ a CT angiogram is also helpful in making the diagnosis.

\section{Gastrointestinal}

Gastro-oesophageal reflux is thought to cause tachypnoea, presumably due to discomfort from oesophagitis, but it would need to be quite severe to cause persistent symptoms; the child would not necessarily be vomiting. A pH study should be diagnostic, and in an infant a dual probe study is preferable in order to take account of any buffering of stomach acid by frequent milk feeds.

Recurrent aspiration of fluid (eg, milk, saliva) can sometimes be silent, so the baby does not necessarily cough, splutter or choke when drinking. It is often idiopathic, sometimes associated with a bulbar palsy, and occasionally anatomical (eg, laryngeal cleft). Diagnosis is made by a speech therapist's clinical assessment, sometimes followed by a videofluoroscopic swallowing study.

\section{Trisomy 21}

Particular consideration in babies with Down's syndrome should be given to congenital heart disease, infection, upper airway anomalies (narrow trachea, laryngomalacia, tracheomalacia and bronchomalacia), aspiration due to gastro-oesophageal reflux or swallowing abnormalities.

\section{OUTCOME}

Experience shows that in the absence of an underlying condition, the tachypnoea usually resolves, but may take as long as 6-12 months. This does mean that the cause in most babies is never determined. One can speculate the improvement is due to maturation of automatic control of breathing (based in the brainstem), response to chemoreceptors, or a change in the mechanical properties (compliance and volumes) of the lungs and chest wall. ${ }^{2}$ In those with a specific diagnosis, the outcome will depend on the actual diagnosis.

Acknowledgements The authors thank Prof Andrew Bush, Dr Siobhán Carr, Dr Mark Rosenthal and Dr Enitan Ogundipe for their advice on the manuscript.

Contributors MLR wrote the cardiology section and reviewed the rest of the article, IMBL wrote the rest of the article.

\section{Competing interests None.}

Provenance and peer review Commissioned; externally peer reviewed.
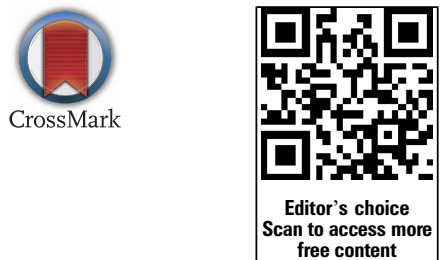

To cite Balfour-Lynn IM, Rigby ML. Arch Dis Child 2015:100:722-727.

Received 16 October 2014

Revised 19 January 2015

Accepted 16 February 2015

Published Online First 9 March 2015

Arch Dis Child 2015;100:722-727.

doi:10.1136/archdischild-2014-306692

\section{REFERENCES}

1 Pasterkamp $H$. The history and physical examination. In: Wilmott RW, Boat TF, Bush A, Chernick V, Deterding RR, Ratjen F, eds. Kendig \& Chernick's disorders of the respiratory tract in children. 8th edn. Philadelphia: Elsevier Saunders, 2012:110-30.

2 Rusconi F, Castagneto M, Gagliardi L, et al. Reference values for respiratory rate in the first 3 years of life. Pediatr 1994;94:350-5.
3 Simoes EA, Roark R, Berman S, et al. Respiratory rate: measurement of variability over time and accuracy at different counting periods. Arch Dis Child 1991;66:1199-203.

4 Berman S, Simoes EA, Lanata C. Respiratory rate and pneumonia in infancy. Arch Dis Child 1991; 66:81-4.

5 Morley CJ, Thornton AJ, Fowler MA, et al. Respiratory rate and severity of illness in babies under 6 months old. Arch Dis Child 1990;65: 834-7.

6 Valman HB, Wright BM, Lawrence C. Measurement of respiratory rate in newborns. $B M J$ 1983;286:1783-4.

7 Balfour-Lynn IM, Field DJ, Gringras P, et al.; Paediatric Section of the Home Oxygen Guideline Development Group of the BTS Standards of Care Committee. BTS guidelines for home oxygen in children. Thorax 2009;64(Suppl 2):ii1-26.

8 Masters IB, Goes AM, Healy L, et al. Age-related changes in oxygen saturation over the first year of life: a longitudinal study. J Paediatr Child Health 1994;30:423-8.

9 Hunt CE, Corwin MJ, Lister G, et al. Longitudinal assessment of hemoglobin oxygen saturation in healthy infants during the first 6 months of age. Collaborative Home Infant Monitoring Evaluation (CHIME) Study Group. J Pediatr 1999;135:580-6.

10 Koppel RI, Druschel CM, Carter T, et al. Effectiveness of pulse oximetry screening for congenital heart disease in asymptomatic newborns. Pediatr 2003;111:451-5.

11 Sasidharan P. An approach to diagnosis and management of cyanosis and tachypnea in term infants. Pediatr Clin North Am 2004;51: 999-1021.

12 Jones RWA, Baumer JH, Joseph MC, et al. Arterial oxygen tension and response to oxygen breathing in differential diagnosis of congenital heart disease in infancy. Arch Dis Child 1976;47:707-15.

13 Sury MR, Harker $H$, Begent J, et al. The management of infants and children for painless imaging. Clin Radiol 2005;60:731-41.

14 Arikan-Ayyildiz Z, Uzuner N, Cakmakçi H, et al. Pulmonary tuberculosis in infants under one year of age. Turk J Pediatr 2011;53:250-4.

15 Faro A, Michelson PH, Ferkol TW. Pulmonary Disease in Cystic Fibrosis. In: Wilmott RW, Boat TF, Bush A, Chernick V, Deterding RR, Ratjen F, eds. Kendig \& Chernick's Disorders of the respiratory tract in children. 8th edn. Philadelphia: Elsevier Saunders, 2012:770-80.

16 Kuo CS, Young LR. Interstitial lung disease in children. Curr Opin Pediatr 2014;26:320-7.

17 Deterding RR, Pye C, Fan LL, et al. Persistent tachypnea of infancy is associated with neuroendocrine cell hyperplasia. Pediatr Pulmonol 2005;40:157-65.

18 Lukkarinen $\mathrm{H}$, Pelkonen A, Lohi J, et al. Neuroendocrine cell hyperplasia of infancy: a prospective follow-up of nine children. Arch Dis Child 2013;98:141-4.

19 Thouvenin G, Abou Taam R, Flamein F, et al. Characteristics of disorders associated with genetic mutations of surfactant protein C. Arch Dis Child 2010;95:449-54.

20 Brody AS, Guillerman RP, Hay TC, et al. Neuroendocrine cell hyperplasia of infancy: diagnosis with high-resolution CT. AJR Am J Roentgenol 2010;194:238-44.

21 Rusakow LS, Khare S. Radiographically occult congenital lobar emphysema presenting as unexplained neonatal tachypnea. Pediatr Pulmonol 2001;32:246-9.

22 Sonnappa S, Cohen G, Ramsay A, et al. A baby with cough and poor feeding. Localised persistent pulmonary interstitial emphysema of the left lung. Eur Respir J 2003;22:182-5. 
23 Aiton NR, Fox GF, Hannam S, et al. Pulmonary hypoplasia presenting as persistent tachypnoea in the first few months of life. BMJ 1996;312:1149-50.

24 Laberge J-M, Puligandla P. Congenital malformations of the lungs and airways. In: Taussig LM, Le Souëf PN, Martinez FD, Landau LI, Morgan WJ, Sly PD, eds. Pediatric respiratory medicine. 2nd edn. Philadelphia: Mosby Elsevier, 2008:907-41.

25 Midyat L, Demir E, Asskin M, et al. Eponym. Scimitar syndrome. Eur J Pediatr 2010;169:1171-7.

26 Bagłaj M. Late-presenting congenital diaphragmatic hernia in children: a clinical spectrum. Pediatr Surg Int 2004;20:658-69.

27 Bowerson M, Nelson VS, Yang LJ. Diaphragmatic paralysis associated with neonatal brachial plexus palsy. Pediatr Neurol 2010;42:234-6.

28 Baughn J, Gershan W, Rao A. Noisy breathing and hemidiaphragm paralysis progressing to respiratory failure in an infant. Pediatr Pulmonol

2011;46:817-19.
29 Gnagi SH, Schraff SA. Nasal obstruction in newborns. Pediatr Clin North Am 2013;60:903-22.

30 Ramsden JD, Campisi P, Forte V. Choanal atresia and choanal stenosis. Otolaryngol Clin North Am 2009;42:339-52

31 Griffin AJ, Ferrara JD, Lax JC, et al. Pulmonary compliance. An index of cardiovascular status in infancy. Am J Dis Child 1972;123:89-95.

32 Phelan PD, Gillam GL, Menahem SA, et al. Respiratory function in infants with a ventricular septal defect. Austral Paed J 1972;8:79-85.

33 Warburton D, Rehan M, Shinebourne EA. Selective criteria for differential diagnosis of infants with symptoms of congenital heart disease. Arch Dis Child 1981;56:94-100.

34 Rowe RD, Hoffmann T. Transient myocardial ischemia of the newborn infant. A form of severe cardiopulmonary distress in full term infants. J Pediatr 1972;81:243-50.
35 Cox GF. Diagnostic approaches to pediatric cardiomyopathy of metabolic genetic etiologies and their relation to therapy. Progr Pediat Cardiol 2007:24:15-25.

36 Rudolph AM. The changes in the circulation after birth. Their importance in congenital heart disease. Circulation 1970;41:343-59.

37 Rudolph AM. High pulmonary vascular resistance after birth. Pathophysiologic considerations and etiologic classification. Clin Paediatr 1980;19:585-90.

38 Daubeney EF, Rigby ML, Niwa K, et al. Paediatric heart disease: a practical guide. Oxford: Wiley-Blackwell, 2012:20-5.

39 Weintraub RG, Nugent AW, Daubeney PEF. Progr Paediatr Cardiol 2007:23:17-24.

40 Benson LN, Freedom RM. The clinical diagnostic approach in congenital heart disease. In Freedom RM, Benson LN, Smallhorn JF. eds. Neonatal heart disease. London: Springer-Verlag, 1992 165-78. 